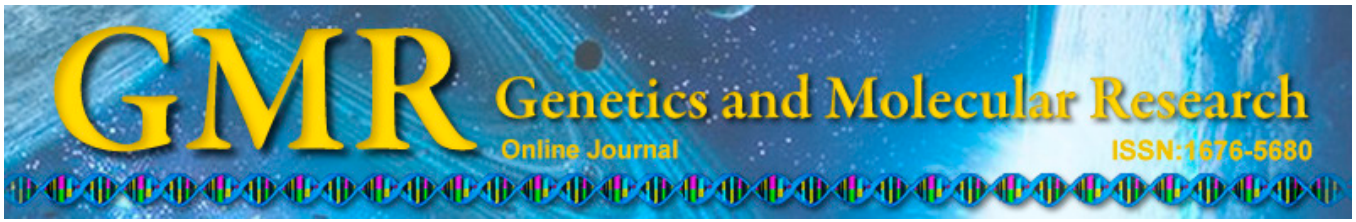

\title{
Association of AGTR1 gene A1166C polymorphism with the risk of heart failure: a meta-analysis
}

\author{
J.A. Zhang', J.R. Li $^{1}$ and Y.J. Qiao ${ }^{2}$ \\ ${ }^{1}$ Emergency Department, Tianjin Hospital, Tianjin, China \\ ${ }^{2}$ Intensive Care Unit, Tianjin People's Hospital, Tianjin, China \\ Corresponding author: J.A. Zhang \\ E-mail: zhangjiao1208@126.com
}

Genet. Mol. Res. 14 (3): 9163-9170 (2015)

Received December 9, 2014

Accepted May 23, 2015

Published August 7, 2015

DOI http://dx.doi.org/10.4238/2015.August.7.26

\begin{abstract}
The aim of this study was to investigate the correlation between the $\mathrm{A} 1166 \mathrm{C}$ polymorphism in the angiotensin II type 1 receptor (AT1R) gene and heart failure (HF) risk using meta-analysis. The PubMed database was searched, and data were extracted independently by two reviewers. Odds ratios (ORs) with corresponding 95\% confidence intervals (CIs) were used to assess the strength of the associations. Statistical analysis was performed using the STATA 12.0 software. The results of the meta-analysis showed no significant association between the $A T 1 R$ A1166C polymorphism and HF risk (AA vs $\mathrm{CC}$ : $\mathrm{OR}=$ $0.72,95 \% \mathrm{CI}=0.31-1.68$; $\mathrm{AA} v s \mathrm{AC}: \mathrm{OR}=0.78,95 \% \mathrm{CI}=0.52-1.18$; dominant model: $\mathrm{OR}=1.37,95 \% \mathrm{CI}=0.92-2.04$; recessive model: $\mathrm{OR}=0.73,95 \% \mathrm{CI}=0.30-1.75$ ). In the subgroup analysis by ethnicity, the results also showed no significant association between A1166C polymorphism and susceptibility to $\mathrm{HF}$ in both Caucasian and Asian populations. In conclusion, this meta-analysis suggests that the $\mathrm{A} 1166 \mathrm{C}$ polymorphism in ATIR may not be associated with susceptibility to HF.
\end{abstract}


Further large and well-designed studies are needed to confirm these conclusions.

Key words: AT1R; Gene polymorphism; Heart failure; Meta-analysis

\section{INTRODUCTION}

Heart failure (HF) is a serious disease that endangers human life (Robertson et al., 2012). A previous study indicated that approximately $20 \%$ of people worldwide will have HF at some point in their lifetime (Lloyd-Jones et al., 2012). Although diagnostic tool intensity and treatments are improving, mortality after onset of HF remains high, ranging from 20-50\% (Packer et al., 2001; Schocken et al., 2008). After much investigation, the causes of the disease are still not well understood. However, there are some risk factors that increase a person's susceptibility for HF, including age, gender, hypertension, coronary artery disease, diabetes, obesity, and lifestyle (Chen et al., 2012). Of these people, only a fraction develop HF, indicating the importance of several other factors. In recent years, many studies have shown that genetic factors also play an important role in the development of HF (Morita et al., 2005; Chen et al., 2012).

The renin angiotensin system (RAS) influences sodium balance, extracellular fluid volume, and systemic vascular resistance (Wang and Staessen, 2000). Angiotensin II is the most important active component of the RAS, which plays an important role in the regulation of blood pressure and vascular homeostasis. This protein mediates its actions via two distinct subtypes of angiotensin II receptors: type 1 receptor (angiotensin II type 1 receptor, AT1R) and type 2 receptor (Miura et al., 2011). The AT1R gene is composed of five exons located on chromosome $3 \mathrm{q}$, where the first four exons encode the 5'-untranslated region (Guo et al., 1994). The A1166C polymorphism (SNP ID: rs5186) is located in the 3 '-untranslated region of $A T 1 R$ and leads to the transversion of an adenine (A) to a cytosine (C) base at the 1166 position (Poirier et al., 1998). A previous meta-analysis found that the A1166C polymorphism in AT1R may be involved in the development of coronary heart disease (Zhang et al., 2013).

In recent years, several studies had been performed to evaluate the relationship between the AT1R A1166C polymorphism and HF risk. However, the results presented in these publications remain controversial. The discrepancies may also be due to the inadequate statistical power of individual studies to detect small or moderate effects. A meta-analysis can be performed to address some of these obstacles by increasing statistical power and assessing generalizability of findings across populations (Salanti et al., 2005). In the present study, therefore, we perform the current meta-analysis to examine whether the A1166C polymorphism is associated with HF.

\section{MATERIAL AND METHODS}

\section{Selection of studies}

All case-control studies assessing the association between the AT1R A1166C polymorphism and HF risk published through December 2014 were identified by searching the PubMed database. There was no language limitation. The following search terms were used: "heart failure/HF", "angiotensin II type 1 receptor/AT1R", "A1166C", and "gene polymorphism" for relevant citations. If sequential or multiple publications from the same data were identified, the publication reporting data from the largest or most recent study were included. 


\section{Inclusion and exclusion criteria}

Studies meeting all of the following criteria were included in our meta-analysis: 1) case control studies, 2) studies that assessed the association between the AT1R A1166C polymorphism and HF risk, 3) provided sufficient information to estimate odds ratios (OR) with its $95 \%$ confidence interval $(95 \% \mathrm{CI})$, and 4$)$ provided data regarding genotype frequency of the A1166C polymorphism. Major exclusion criteria included: 1) no control population, 2) no available genotype frequency, and 3) duplicated studies.

\section{Data extraction}

To improve the reliability of data, information was extracted from all eligible publications by two investigators independently according to the following characteristics: 1) name of the first author, 2) year of publication, 3) country, 4) ethnicity, 5) sample size of cases and controls, 6) genotype distribution in cases and controls, and 7) $\mathrm{P}$ value for Hardy-Weinberg equilibrium (HWE) test in controls. For conflicting evaluations, an agreement was reached following a discussion.

\section{Statistical analysis}

The association between the $A T 1 R$ A1166C polymorphism and HF was estimated by calculating pooled $\mathrm{OR}$ and $95 \% \mathrm{CI}$ under a codominant (AA vs CC, AA vs AC), a dominant $(\mathrm{CC}+\mathrm{AC}$ vs $\mathrm{AA})$, or a recessive model $(\mathrm{AA}+\mathrm{AC}$ vs $\mathrm{CC})$. The Fisher exact test was used to assess the HWE with the significance set at $\mathrm{P}<0.05$. Between-study heterogeneities were estimated using the $\mathrm{I}^{2}$ test. $\mathrm{I}^{2}$ values of 25,50 , and $75 \%$ were defined as low, moderate, and high estimates, respectively (Wang and Pan, 2014). If a heterogeneity was found among the studies, the pooled OR was estimated using the fixed-effect model $\left(\mathrm{P}>0.10\right.$ or $\left.\mathrm{I}^{2}<50 \%\right)$. Otherwise, the random-effect model was used to estimate the pooled OR. Subgroup analysis by ethnicity was performed to examine the source of heterogeneity. Sensitivity analysis was performed by excluding one study at a time. Publication bias was investigated by Begg's funnel plot, and $\mathrm{P}<$ 0.05 was considered as a statistically significant publication bias. Data analysis was performed using STATA version 12 (StataCorp. LP. College Station, TX, USA).

\section{RESULTS}

\section{Characteristics of the studies included}

The search strategy retrieved 33 potentially relevant studies. Based on the inclusion criteria, only 5 case-control studies (Gubaev et al., 2006; Amir et al., 2009; Zakrzewski-Jakubiak et al., 2008; Wu et al., 2008; Cameron et al., 2006) with full-text were included in this meta-analysis and 28 studies were excluded. The flow chart of study selection is summarized in Figure 1. These 5 case-control studies included a total of 545 cases and 986 healthy controls. The published year of the studies included ranged from 2006 to 2014. The study characteristics are presented in Table 1, and contain the population studies of 4 Caucasians (Gubaev et al., 2006; Zakrzewski-Jakubiak et al., 2008; Cameron et al., 2006) and 2 Asians (Amir et al., 2009; Cameron et al., 2006). The source of the controls was based on healthy populations. The 
genotype frequencies of the controls from five studies were in agreement with HWE except for Cameron et al. (2006).

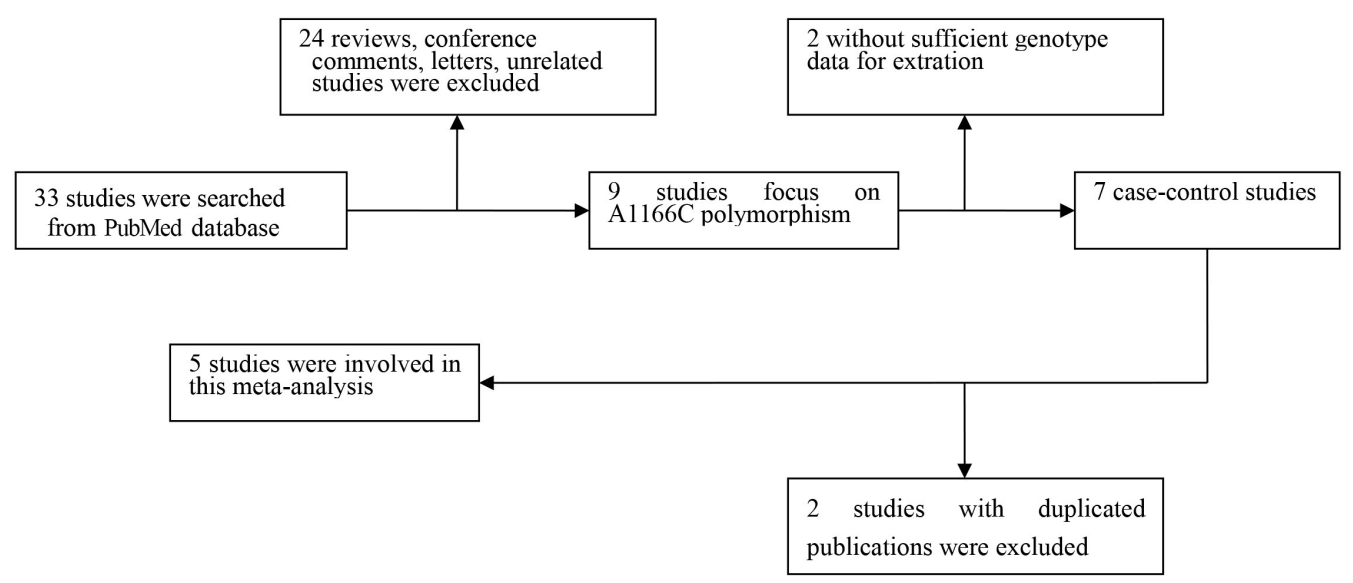

Figure 1. Flow chart showing study selection procedure.

Table 1. Characteristics of literature included in the meta-analysis.

\begin{tabular}{|c|c|c|c|c|c|c|c|c|c|c|c|}
\hline \multirow[t]{2}{*}{ Study included } & \multirow[t]{2}{*}{ Year } & \multirow[t]{2}{*}{ Area } & \multirow[t]{2}{*}{ Race } & \multirow[t]{2}{*}{ Cases/Controls } & \multicolumn{3}{|c|}{ Genotypes for cases } & \multicolumn{3}{|c|}{ Genotypes for controls } & \multirow[t]{2}{*}{ HWE test } \\
\hline & & & & & $\mathrm{AA}$ & $\mathrm{AC}$ & $\mathrm{CC}$ & AA & $\mathrm{AC}$ & $\mathrm{CC}$ & \\
\hline Gubaev & 2006 & Bashkortostan Republic & Caucasian & $62 / 156$ & 39 & 21 & 2 & 112 & 37 & 7 & 0.10 \\
\hline Gubaev & 2006 & Bashkortostan Republic & Caucasian & $31 / 107$ & 19 & 9 & 3 & 74 & 32 & 1 & 0.22 \\
\hline Amir & 2009 & Israel & Asian & $134 / 200$ & 74 & 50 & 10 & 104 & 79 & 17 & 0.72 \\
\hline Zakrzewski-Jakubiak & 2008 & Canada & Caucasian & $58 / 110$ & 23 & 33 & 2 & 48 & 49 & 13 & 0.93 \\
\hline $\mathrm{Wu}$ & 2008 & China & Asian & $148 / 286$ & 122 & 22 & 4 & 270 & 16 & 0 & 0.63 \\
\hline Cameron & 2006 & New Zealand & Caucasian & $112 / 127$ & 45 & 30 & 37 & 53 & 48 & 26 & 0.02 \\
\hline
\end{tabular}

\section{Quantitative synthesis}

A summary of the meta-analysis on the association between AT1R A1166C polymorphism and HF risk is provided in Table 2 and Figure 2. Overall, we did not find a significant association between the $\mathrm{A} 1166 \mathrm{C}$ polymorphism and risk of $\mathrm{HF}$ (AA vs CC: OR $=0.72,95 \% \mathrm{CI}=0.31-1.68 ; \mathrm{AA} v s \mathrm{AC}: \mathrm{OR}=0.78,95 \% \mathrm{CI}=0.52-1.18$; dominant model: $\mathrm{OR}=1.37,95 \% \mathrm{CI}=0.92-2.04$; recessive model: $\mathrm{OR}=0.73,95 \% \mathrm{CI}=0.30-1.75)$. In the subgroup analysis based on ethnicity, the studies included were divided into Caucasian and Asian populations. These results also showed no significant association between the A1166C polymorphism and susceptibility to HF in both Caucasian and Asian populations. Sensitivity analysis was performed by omission of one non-HWE study (Cameron et al., 2006) and the result was not altered, indicating that the meta-analysis was statistically significant (Table 2). 
Table 2. Summary ORs and 95\%CI of the AT1R gene A1166C polymorphism with heart failure risk.

\begin{tabular}{|c|c|c|c|c|c|c|c|c|c|c|}
\hline \multirow{3}{*}{$\begin{array}{l}\text { Subgroup } \\
\text { Overall }\end{array}$} & \multirow{3}{*}{$\begin{array}{l}\text { Genetic model } \\
\text { AA vs CC }\end{array}$} & \multirow{2}{*}{\multicolumn{2}{|c|}{$\frac{\text { Sample size }}{\text { Case Control }}$}} & \multirow{3}{*}{$\begin{array}{l}\text { Type of model } \\
\text { Random }\end{array}$} & \multicolumn{2}{|c|}{ Test of heterogeneity } & \multicolumn{2}{|c|}{ Test of association } & \multicolumn{2}{|c|}{ Test of publication bias } \\
\hline & & & & & \multirow{2}{*}{$\begin{array}{c}\mathrm{I}^{2} \\
57.9 \%\end{array}$} & \multirow{2}{*}{$\frac{P}{0.04}$} & \multirow{2}{*}{$\begin{array}{c}\mathrm{OR} \\
0.72\end{array}$} & \multirow{2}{*}{$\frac{95 \% \mathrm{CI}}{0.31-1.68}$} & \multirow{2}{*}{$\begin{array}{c}\mathrm{z} \\
0.73\end{array}$} & \multirow{2}{*}{$\begin{array}{c}\mathrm{P} \\
0.46\end{array}$} \\
\hline & & 545 & 986 & & & & & & & \\
\hline & $\mathrm{AA} v s \mathrm{AC}$ & & & Random & $59.8 \%$ & 0.03 & 0.78 & $0.52-1.18$ & 0.73 & 0.46 \\
\hline & the dominant model & & & Random & $61.8 \%$ & 0.02 & 1.37 & $0.92-2.04$ & 0.73 & 0.46 \\
\hline & the recessive model & & & Random & $63.6 \%$ & 0.02 & 0.73 & $0.30-1.75$ & 0.73 & 0.46 \\
\hline \multirow[t]{4}{*}{ Asians } & $\mathrm{AA} v s \mathrm{CC}$ & 282 & 486 & Random & $77.5 \%$ & 0.04 & 0.33 & $0.01-7.81$ & 0.00 & 1.00 \\
\hline & $\mathrm{AA} v s \mathrm{AC}$ & & & Random & $88.4 \%$ & 0.00 & 0.62 & $0.19-2.08$ & 0.00 & 1.00 \\
\hline & the dominant model & & & Random & $91.8 \%$ & 0.00 & 1.35 & $0.95-1.93$ & 0.00 & 1.00 \\
\hline & the recessive model & & & Random & $75.1 \%$ & 0.05 & 0.35 & $0.02-6.89$ & 0.00 & 1.00 \\
\hline \multirow[t]{4}{*}{ Caucasians } & $\mathrm{AA} v s \mathrm{CC}$ & 263 & 500 & Random & $59.2 \%$ & 0.06 & 0.77 & $0.26-2.34$ & 0.00 & 1.00 \\
\hline & $\mathrm{AA} v s \mathrm{AC}$ & & & Fixed & $15.9 \%$ & 0.31 & 0.87 & $0.62-1.22$ & 0.00 & 1.00 \\
\hline & the dominant model & & & Fixed & $0.0 \%$ & 0.86 & 1.23 & $0.90-1.68$ & 0.00 & 1.00 \\
\hline & the recessive model & & & Random & $68.5 \%$ & 0.02 & 0.79 & $0.23-2.73$ & 0.00 & 1.00 \\
\hline Consistent with & $\mathrm{AA} v s \mathrm{CC}$ & 433 & 859 & Random & $62.6 \%$ & 0.03 & 0.69 & $0.21-2.33$ & 0.73 & 0.46 \\
\hline \multirow[t]{3}{*}{ HWE } & $\mathrm{AA} v s \mathrm{AC}$ & & & Random & $56.4 \%$ & 0.06 & 0.69 & $0.45-1.08$ & 0.73 & 0.46 \\
\hline & the dominant model & & & Random & $67.9 \%$ & 0.01 & 1.46 & $0.90-2.39$ & 0.73 & 0.46 \\
\hline & the recessive model & & & Random & $64.3 \%$ & 0.02 & 0.74 & $0.22-2.53$ & 0.73 & 0.46 \\
\hline
\end{tabular}

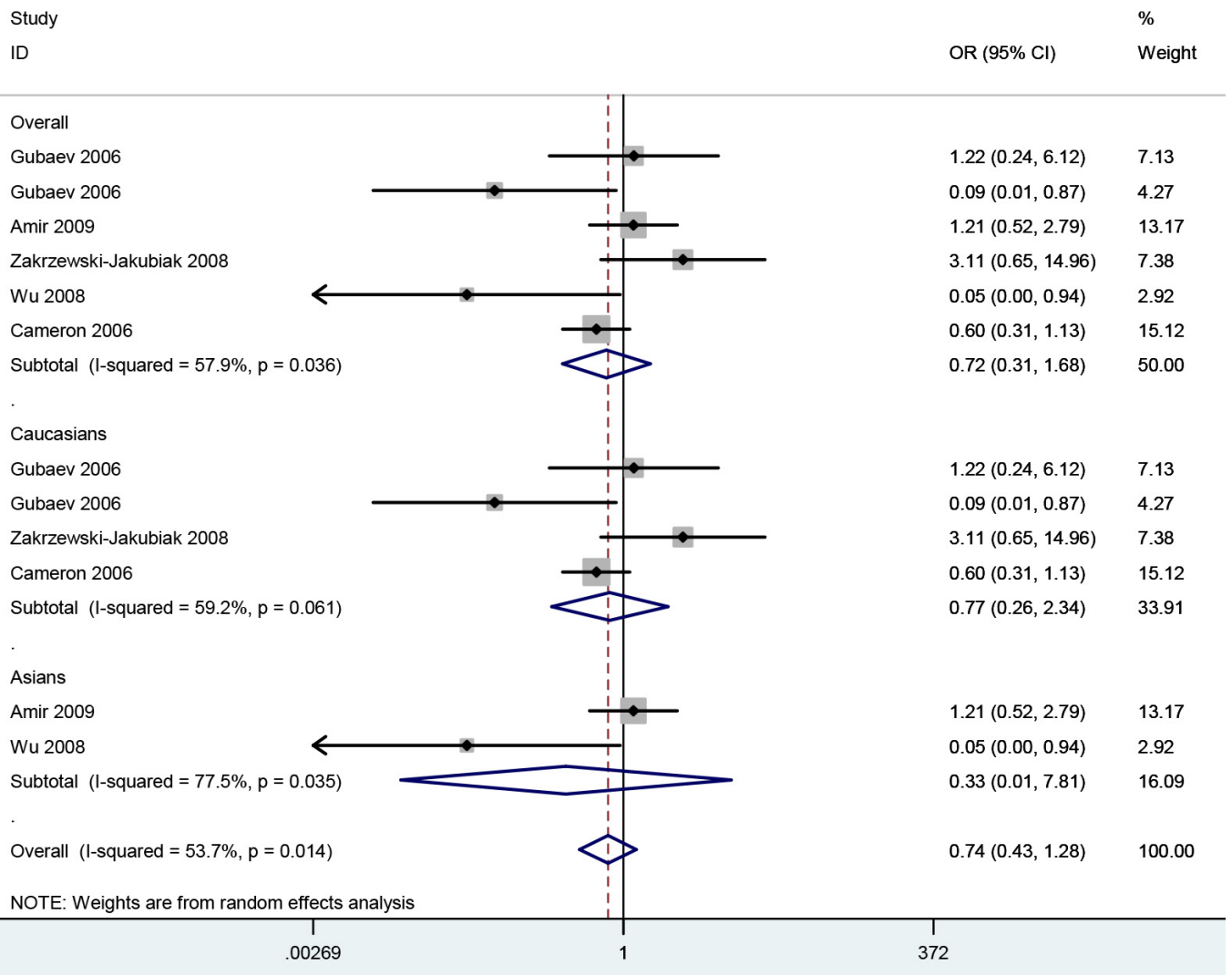

Figure 2. Meta-analysis of the relationship between the A1166C polymorphism in the AT1R gene and HC risk for AA $v s$ CC. 


\section{Publication bias}

Publication bias of the literature was assessed by Begg's funnel plot (Figure 3). The funnel plot was used to measure the asymmetry of the funnel plot. Results showed that there was no publication bias (Table 2; all $\mathrm{P}>0.05$ ).

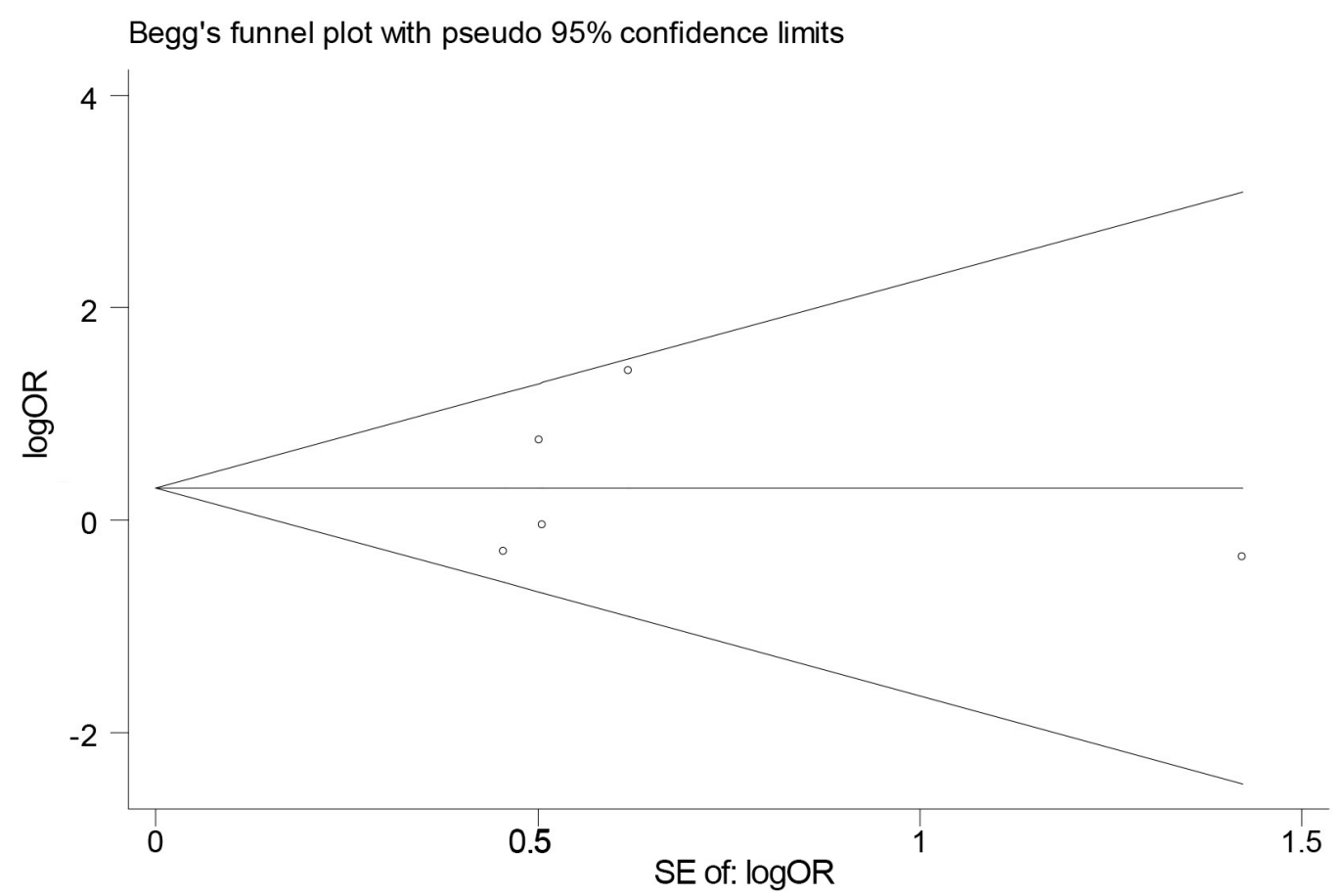

Figure 3. Begg's funnel plot of publication bias for the A1166C polymorphism in the AT1R gene and heart failure risk for AA $v s \mathrm{CC}$.

\section{DISCUSSION}

HF is a major cause of mortality worldwide, and it is estimated that by 2030 an additional 3 million people will have developed heart failure, which is a $25.0 \%$ increase in prevalence from 2010 in the United States of America (Heidenreich et al., 2011). However, the pathogenesis, which may be triggered by genetic as well as environmental factors, is still not fully understood. The RAS plays a key role in the pathophysiology of HF, and its chronic stimulation negatively affects the already failing heart through increased vasoconstriction, sodium and water retention, heart remodeling, and myocardial fibrosis (Weber et al., 2001). Indeed, a previous study has found that the angiotensinogen gene M235T polymorphism might be associated with increased risk of heart failure in Caucasians (Chen et al., 2012). The AT1R is the primary pathogenic effector for angiotensin II. In addition, several studies have found an association between the A1166C polymorphism and HF while others did not, suggesting that it may serve as a possible risk factor for HF. In the present study, we investigated whether the A1166C polymorphism is associated with the risk of HF by performing a meta-analysis. 
Our meta-analysis quantitatively assessed the association between the $\mathrm{A} 1166 \mathrm{C}$ polymorphism in ATIR and HF risk. The current meta-analysis included 545 heart failure patients and 986 controls and explored the association between the A1166C polymorphism and HF risk. To the best of our knowledge, this is the first meta-analysis assessing the relationship between the A1166C polymorphism and the risk of HF. The main meta-analysis results did not show any significant association between the A1166C polymorphism and HF risk. Considering that the result may be affected by ethnicity, we performed a race-related subgroup analysis, and no significant association was found in both Caucasian and Asian populations. Deviation of allelic distributions from HWE may contribute to between-study heterogeneity, and thus, sensitivity analysis was performed by limiting this meta-analysis to those studies that are consistent with HWE. No significant changes were observed when this analysis was performed, which revealed that this meta-analysis was reliable realistic and believable. As this meta-analysis contained only a small number of eligible studies, these results still need further investigation.

The effect of the A1166C polymorphism in ATIR might have a limited impact on $\mathrm{HF}$, as the development of $\mathrm{HF}$ is likely due to the joint effect of multiple genes and gene-environment interactions. The potential function of the A1166C polymorphism might be affected by genegene interactions. A previous study demonstrated that the ACE I/D polymorphism and ATIR A1166C polymorphism synergistically increased HF risk (Wu et al., 2008). In addition, the haplotype alleles formed in $A T 1 R$ (rs16860760, rs389566, and the A1166C polymorphism) were associated with increased risk of HF (Wu et al., 2009). Owing to insufficient available data, further studies of gene-environment interaction should be taken into consideration in future analyses.

Several limitations of our study should be noted. First, the sample size is still relatively small and may not provide sufficient power to estimate the association between the A1166C polymorphism and HF risk. Therefore, more studies with larger sample sizes are needed to accurately provide a more representative statistical analysis. Second, the effect of potential gene-gene and gene-environment interactions could not be addressed in this meta-analysis. Third, any meta-analysis is retrospective research that is subject to methodological limitations.

In conclusion, our study indicated that the A1166C polymorphism in AT1R may be not associated with an increased risk of HF. Moreover, further studies estimating the effect of gene-gene and gene-environment interactions may eventually provide a better and more comprehensive understanding of the association.

\section{Conflicts of interest}

The authors declare no conflict of interest.

\section{REFERENCES}

Amir O, Amir RE, Paz H, Attias E, et al. (2009). Relation between AT1R gene polymorphism and long-term outcome in patients with heart failure. Cardiology 112: 151-157.

Cameron VA, Mocatta TJ, Pilbrow AP, Frampton CM, et al. (2006). Angiotensin type-1 receptor A1166C gene polymorphism correlates with oxidative stress levels in human heart failure. Hypertension 47: 1155-1161.

Chen S, Zhang L, Wang HW, Wang XY, et al. (2012). The M235T polymorphism in the angiotensinogen gene and heart failure: a meta-analysis. J. Renin Angiotensin Aldosterone Syst. 15: 190-195.

Gubaev KI, Nasibullin TR, Zakirova AN and Mustafina OE (2006). Association of polymorphic markers I/D of gene $\mathrm{ACE}$ and A1166C of gene AT2R1 with ischemic chronic heart failure in the Russian and Tatar populations of Bashkortostan Republic. Genetika 42: 1712-1717. 
Guo DF, Furuta H, Mizukoshi M and Inagami T (1994). The genomic organization of human angiotensin II type 1 receptor. Biochem. Biophys. Res. Commun. 200: 313-319.

Heidenreich PA, Trogdon JG, Khavjou OA, Butler J, et al. (2011). Forecasting the future of cardiovascular disease in the United States: a policy statement from the American Heart Association. Circulation 123: 933-944.

Lloyd-Jones DM, Larson MG, Leip EP, Beiser A, et al. (2002). Lifetime risk for developing congestive heart failure: the Framingham Heart Study. Circulation 106: 3068-3072.

Miura S, Karnik SS and Saku K (2011). Review: angiotensin II type 1 receptor blockers: class effects versus molecular effects. J. Renin Angiotensin Aldosterone Syst. 12: 1-7.

Morita H, Seidman J and Seidman CE (2005). Genetic causes of human heart failure. J. Clin. Invest. 115: 518-526.

Packer M, Coats AJS, Fowler MB, Katus HA, et al. (2001). Effect of carvedilol on survival in severe chronic heart failure. N. Engl. J. Med. 344: 1651-1658.

Poirier O, Georges JL, Ricard S, Arveiler D, et al. (1998). New polymorphisms of the angiotensin II type 1 receptor gene and their associations with myocardial infarction and blood pressure: the ECTIM study. J. Hypertens. 16: 1443-1447.

Robertson J, McElduff P, Pearson S, Henry DA, et al. (2012). The health services burden of heart failure: an analysis using linked population health data-sets. BMC Health Serv. Res. 12: 103.

Salanti G, Sanderson S and Higgins JP (2005). Obstacles and opportunities in meta-analysis of genetic association studies. Genet. Med. 7: 13-20.

Schocken DD (2008). American Society for Preventive Cardiology. Prev. Cardiol. 11: 127-128.

Wang JG and Staessen JA (2000). Genetic polymorphism in the renin-angiotensin system: relevance for susceptibility to cardiovascular disease. Eur. J. Pharmacol. 410: 289-302.

Wang YJ and Pan Y (2014). The M235T polymorphism in the angiotensinogen gene and myocardial infarction risk: a meta-analysis. J. Renin Angiotensin Aldosterone Syst. 15: 294-300.

Weber KT (2001). Aldosterone in congestive heart failure. N. Engl. J. Med. 345: 1689-1697.

Wu CK, Tsai CT, Hwang JJ, Luo JL, et al. (2008). Renin-angiotensin system gene polymorphisms and diastolic heart failure. Eur. J. Clin. Invest. 38: 789-797.

Wu CK, Tsai CT, Chang YC, Luo JL, et al. (2009). Genetic polymorphisms of the angiotensin II type 1 receptor gene and diastolic heart failure. J. Hypertens. 27: 502-507.

Zakrzewski-Jakubiak M, de Denus S, Dubé MP, Bélanger F, et al. (2008). Ten renin-angiotensin system-related gene polymorphisms in maximally treated Canadian Caucasian patients with heart failure. Br. J. Clin. Pharmacol. 65: $742-751$.

Zhang K, Zhou B and Zhang L (2013). Association study of angiotensin II type 1 receptor: A1166C (rs5186) polymorphism with coronary heart disease using systematic meta-analysis. J. Renin Angiotensin Aldosterone Syst. 14: 181-188. 